\title{
NICE guidance on long-term sickness and incapacity
}

\author{
Mark Gabbay, Lorraine Taylor, Linda Sheppard, Jim Hillage, Clare Bambra,
} Fiona Ford, Richard Preece, Nichole Taske and Michael P Kelly

\section{ABSTRACT}

Long-term sickness absence and incapacity benefits (disability pension) rates have increased across industrialised countries. Effective measures are needed to support return to work. The recommendations of this guidance were informed by the most appropriate available evidence of effectiveness and costeffectiveness. Public health evidence was provided by research using a variety of study designs that attempted to determine the outcome of a particular intervention by evaluating status before and after the intervention had been effected, and was not limited to randomised control trials. Where the evidence base was depleted or underdeveloped, expert witnesses were called to give their opinion on the best available evidence and emerging interventions. The process enabled challenge and contestability from stakeholder groups at different points as the guidance was developed. Forty-five heterogeneous studies were included in the review of interventions to reduce long-term sickness absence and transitions from short-term to long-term absence (mainly covering the former and also mainly examining musculoskeletal conditions). The analysis of evidence was restricted to descriptive synthesis. Three general themes emerged from an analysis of the studies that were more likely to report positive results: early interventions; multidisciplinary approaches; and interventions with a workplace component. Two further reviews were undertaken, one on interventions to reduce the re-occurrence of sickness absence, which identified seven studies on lower back pain, and concluded that early intervention and direct workplace input are important factors. The final evidence review focused on six studies of interventions for those in receipt of incapacity benefit. The evidence was that work-focused interviews coupled with access to tailored support are effective and cost-effective interventions. Practitioners should consider the impact of interventions and management options on work ability for patients of working age. Work ability should be considered a key outcome for future intervention studies.

Keywords

evidence-based medicine; guideline; sick leave; sick leave, cost; work capacity evaluation.

\section{INTRODUCTION}

Long-term sickness absence and incapacity benefits (disability pension) rates have increased across industrialised countries. In 2007, 5.8\% of the Organisation for Economic Co-operation and Development (OECD) working-age population received such benefits. ${ }^{1}$ On average, OECD countries spend $0.8 \%$ of gross domestic product (GDP) on public sickness absence benefits and $1.2 \%$ of GDP on disability pensions (such as incapacity benefit). The probability of returning to work after being granted a disability pension is just $2 \%$ annually across OECD countries. ${ }^{1}$ Effective measures to activate long-standing benefit recipients and to prevent the flow of people from sickness absence to disability pension are a high priority. A recent comprehensive review of the health of Europe's largest employer (the NHS) has shown important

M Gabbay, MD, FRCGP, professor of general practice and head of Department of Health Services Research, Division of Primary Care, University of Liverpool, Liverpool. N Taske, PhD, senior technical adviser, Centre for Clinical Practice; L Taylor, BSc, MSc, technical analyst; MP Kelly, BA, MPhil, PhD, director, Centre for Public Health Excellence, National Institute for Health and Clinical Excellence (NICE), London. L Sheppard, PhD, technical analyst, Centre for Public Health Excellence, NICE Manchester. J Hillage, BA, MSc, FRSA, director of research, Institute for Employment Studies, Brighton. C Bambra, BSc, $M A, P h D$, professor of public health policy, Department of Geography, deputy director, Wolfson Research Institute, University of Durham, Stockton-on-Tees. F Ford, MBE, MRCGP, senior lecturer, General Practice Faculty of Health and Social Care, University of Central Lancashire, Preston. R Preece, $M B A$, FFOM, FACOEM, consultant in occupational medicine, Mid-Cheshire Hospitals NHS Foundation Trust, Crewe.

\section{Address for correspondence}

Professor Mark Gabbay, University of Liverpool, Division of Primary Care, Block B, Waterhouse Buildings, 1-5 Brownlow Street, Liverpool, L69 3GL. E-mail: m.b.gabbay@liverpool.ac.uk

Submitted: 29 October 2010; final acceptance: 29 October 2010 .

(B)British Journal of General Practice

This is the full-length article (published online $28 \mathrm{Feb} 2011$ ) of an abridged version published in print. Cite this article as: Br J Gen Pract 2011; DOI: 10.3399/bjgp11X561221. 
associations between health and wellbeing, sickness absence, and key indicators of organisational performance. The authors emphasised the need for effective interventions to improve the health of the workforce to reduce absenteeism rates.

It is within this broad international context that in March 2009 the National Institute for Health and Clinical Excellence (NICE) issued guidance on managing long-term sickness absence and incapacity for work, as part of its public health portfolio. ${ }^{3}$ Its publication coincides with a landmark period in welfare reform in the UK, ${ }^{4}$ as well as the strategic review of work and health following the publication of Dame Carol Black's review. ${ }^{5}$ Primarily aimed at employers and managers, NHS clinicians, and commissioners, the guidance is also relevant internationally. ${ }^{3}$

The guidance uses the best available evidence to make recommendations on which interventions, strategies, and programmes are effective and costeffective in terms of reducing short-term and longterm sickness absence, as well as enhancing return to paid work for those in receipt of incapacity benefit (or other similar benefits). Long-term sickness absence was defined as absence of 4 or more weeks, and short-term as sickness absences of less than 4 weeks.

This paper reports the background to the production of the guidance, including a brief summary of the methods and available evidence used to produce the guidance. It also provides a synthesis of the available evidence, and a discussion of its strengths and key gaps in the existing evidence base, alongside consideration of a number of contextual factors relating to the recommended interventions and activities.

\section{Sickness absence}

International comparisons of sickness absence rates are limited in number, and vary in the methods used to capture relevant data. This limits the validity and reliability of international comparisons. ${ }^{6}$ However, there is evidence of significant variations, with rates of at least 1 day's absence in the previous year in European countries ranging from $6.7 \%$ to $24.0 \%$, with the UK rate being $11.7 \% .^{7}$

The quality and accuracy of data on sickness absence in the UK is also variable. ${ }^{8-10}$ The most recent surveys of UK employers found that UK employees in 2008 were absent for an average of 3.3\% (about 7.4 working days) of the time they were due to spend working. Sixty-nine per cent of these reported periods of absence involved 7 days or less, $17 \%$ involved between 8 days and 4 weeks, and $17 \%$ lasted for 4 weeks (20 working days) or longer. ${ }^{11}$ The 2008 Confederation of British Industry survey shows

\section{How this fits in}

Sickness absence is a growing concern, and GPs remain at the centre of solutions to manage certification and signposting for advice and support. NICE provides evidence reviews and recommendations on a wide range of health related topics, but those relating to public health are less straightforward than conventional treatment-related technology reviews. This paper summarises the NICE guidance, the evidence underpinning it, and the limitations of this evidence.

that $95 \%$ of absences last less than 20 days, but the remaining $5 \%$ account for $40 \%$ of all lost time. ${ }^{12}$

In 2006, an estimated 175 million working days were lost in Britain due to sickness absence. ${ }^{5}$ The annual cost of sickness absence and worklessness is estimated to be in excess of $£ 100$ billion, greater than the UK annual NHS budget, with mental ill health costing UK business around £26 billion per year. ${ }^{13} \mathrm{~A}$ recent study of long-term sickness absence rates in the UK over a decade highlights substantial regional variation, with rates highest in areas with loss of manufacturing jobs. It is also noted that most of the reduction in overall numbers of long-term sickness absence benefits ( $4 \%$ in a decade) reflects a fall in those entering into the benefit (inflow) rather than increases in those getting work or entering retirement (outflow). ${ }^{14}$

The commonest causes of long-term sickness absence among manual workers (across all sectors in the UK) are acute medical conditions, followed by back pain, musculoskeletal injuries, stress, and mental health problems.

Among non-manual workers (across all sectors), the most common causes are stress, acute medical conditions, mental health problems (such as depression and anxiety), musculoskeletal injuries, and back pain. ${ }^{11} \mathrm{~A}$ survey of all sicknotes collected from nine practices in a region of England over a year suggests that mild to moderate mental health problems are now commoner than musculoskeletal causes of absence, and prolonged absence in particular..$^{15}$ This is a common change across OECD countries. ${ }^{1}$

Sickness absence rates vary by sex, age, occupation, sector, region, and the size of the workplace. ${ }^{8,12}$ Individuals who are out of work for long periods of time due to sickness, experience a drop in income, which can result in poverty and social exclusion. ${ }^{16,17}$ In addition, the longer someone is not working, the less likely they are to return to work; consequently, most claimants absent for 6 months or more have an $80 \%$ chance of being off work for 5 years. $^{18}$

\section{Disability pension (incapacity benefits)}

In the UK, people who are medically assessed as 
being incapable of work due to illness, and who have contributed sufficient National Insurance (social security) payments, are entitled to claim incapacity benefit. ${ }^{19}$ Incapacity benefit is similar in remit to the long-term sickness and disability insurance schemes of other western countries, such as the US's social security disability insurance and the disability pensions of Germany and Sweden. In the UK, as elsewhere in Europe, rates of incapacity benefit claims have increased rapidly from 0.5 million in 1975 to 2.6 million in $2007 . .^{20}$ Around $7 \%$ of the UK working-age population claims social security benefits on the grounds of ill health. ${ }^{1}$ This is above the OCED average of $5.8 \%$. Incapacity benefit claims also account for the largest proportion of UK social security expenditure (11\% in 2005), around £8 billion per annum, or $1.8 \%$ of GDP. ${ }^{1}$ The two principal health conditions upon which such claims are based are musculoskeletal disorders and, increasingly, mental health problems, particularly anxiety and depression. Internationally, the pattern is similar, with mental health problems accounting for one-third of new disability claims across OECD countries. Mental ill health is also a more frequent diagnosis among younger claimants. ${ }^{1,21}$

In October 2008, a new benefit, the 'employment support allowance' was introduced. ${ }^{4}$ This replaces incapacity benefit and involves a two-tier system of benefits in which more severely ill or disabled people considered unable to work or with limited work capacity due to their physical or mental condition receive a higher level of benefit with no conditionality. However, those who are deemed 'sick but able to work' only receive full benefits if they participate in employment initiatives such as 'Pathways to Work'. ${ }^{22}$

\section{METHOD}

NICE has clear underpinning methodological and process principles for both clinical and public health guidance development. ${ }^{3,23}$ The general principles for public health are as follows. Recommendations are informed by the most appropriate available evidence of effectiveness and cost-effectiveness. In public health guidance, evidence may be provided by research using any study design that attempts to determine the outcome of a particular intervention by evaluating status before and after the intervention has been effected, and is not limited to randomised controlled trials. Where the evidence base is depleted or underdeveloped, expert witnesses can be called by NICE to give their opinion on the best available evidence and emerging interventions. Evidence from research that has evaluated the costeffectiveness of interventions is also sought. Costeffectiveness is assessed using the quality-adjusted life year (QALY). Processes are open and transparent, and allow challenge and contestability from stakeholder groups at different points as the guidance is developed. Where scientific and other values impinge on the assessment process, these are made explicit. And finally, all activities are, and must be seen to be, independent of government, industry, and other vested interests. ${ }^{23}$

The guidance development process starts when a 'referral' is received from the health minister. The referral about long-term sickness was to produce guidance for primary care and employers on the management of long-term sickness and incapacity'. Referrals typically contain no more detail than this. Once the referral is made, government officials and ministers take no further part in the process until the work is published.

The NICE technical team supports guidance production. They draft a scope, outlining the proposed programme of work, incorporating the key questions to be answered by the guidance, and describing the populations, settings, and interventions that would be included to initiate the process.

This is put out to external consultation with stakeholders, responses are collated, and they are accessible on the web. Once amended, the final version becomes the basis for the guidance.

\section{Gathering the evidence}

Evidence is searched for and screened for topic relevance by a review team of academic and research contractors commissioned by NICE, and then appraised using well-defined inclusion and exclusion criteria ${ }^{3}$ to determine the quality of the evidence, its appropriateness to answer the research questions set out in the scope, and its applicability to specific populations and settings in England.

Following this protocol, NICE commissioned reviews of evidence on interventions, strategies, programmes, and policies, which aim to:

- reduce the number of employees who move from short-term to long-term sickness absence, and to help employees on long-term sickness absence return to work;

- reduce the number of employees who take longterm sickness absence on a recurring basis; and

- help recipients of incapacity benefits return to employment (paid and unpaid).

The evidence was summarised into concise statements describing the strength of the evidence (data quality, quantity, consistency, and applicability to the populations of interest). ${ }^{3}$ Details of the review team and their reports can be found in the NICE publication. ${ }^{3}$ Where relevant effectiveness data were 
available, an economic analysis of a selected number of interventions was produced.

A series of five expert papers was also required to cover important themes and emerging interventions that had not been identified by the literature searches used to develop the evidence reviews:

- 'expert patients' programme;

- condition management;

- discrimination in the labour market;

- regional employability programmes; and

- evaluation of Camden GP surgery pilot.

The role of the programme development group The assembled evidence is considered by the programme development group (PDG; a committee comprising professional, lay, and academic experts appointed by NICE following public advertisement and transparent interview procedures), who, supported by the NICE technical team, then craft the recommendations. They meet monthly and use an iterative approach to formulate the recommendations and supporting considerations. This includes consensus on the areas on which to build recommendations, the populations benefiting from the recommendations (target population), and the groups responsible for ensuring the recommendations would be implemented.

\section{RESULTS}

\section{Review findings}

Some 45 studies were included in the review of interventions to reduce long-term sickness absence and transitions from short-term to long-term absence (mainly covering the former and also mainly examining musculoskeletal conditions). The studies were heterogeneous and no two studies measured the same population, intervention, or outcome. This meant that the analysis of evidence was restricted to descriptive synthesis.

Three general themes emerged from an analysis of the studies:

- early interventions or studies that examine populations with a similar, specified length of absence were more likely to report positive results (although this is not a consistent finding across all such studies) than those with later interventions or more mixed populations;

- on balance, studies of multidisciplinary approaches included in the review were more likely to report positive results in terms of effectiveness and cost-effectiveness than studies of singlemodality interventions; and

- studies with a workplace component (including vocational counselling) were also more likely to report successful outcomes than those that did not include such an element.

Additionally, one study ${ }^{24}$ (using a model developed by Haldorsen et $a{ }^{25}$ ) found that a return-to-work prognosis measured at the start of the intervention was important in determining the level of intervention required to achieve return to work for individual participants. This suggests that efficacy is enhanced if interventions are designed to take into account individual differences in return-to-work prognoses.

Eleven of the papers (that is, fewer than onequarter) contained sufficient evidence to be included in the cost-effectiveness analysis of interventions to reduce long-term sickness absence. The papers covered a range of interventions, again mainly for musculoskeletal conditions: six were multidisciplinary and four were exercise-based interventions for low-back or musculoskeletal pain, and one was a psychological-based intervention for minor mental disorders. In each case, the intervention was found to be cost-effective in terms of return to work.

The separate review covering interventions to reduce the number of employees who take long-term sickness absence on a recurring basis included seven effectiveness studies (three of which were included in the cost-effectiveness analysis), and all were concerned with lower-back pain. Again, the review found that the interventions that were successful in reducing the re-occurrence of longterm sickness absence shared certain key characteristics:

- most involved early interventions; and

- the interventions tended to involve some direct workplace input, either through design or assessment, or workplace adaptation and delivery.

The final review examined UK interventions designed to help people in receipt of disability (incapacity) benefit to return to full-time or part-time employment. This review covered a different population group to the other evidence reviews, which focused on absentee employees. This last review found little evidence that met the inclusion criteria (six studies in all, mainly relating to the Pathways to Work pilot programme). However, the evidence reviewed did indicate that an intervention involving a work-focused interview coupled with access to tailored support to meet health or employability needs was effective and cost-effective at increasing the rate of return to work among incapacity benefit recipients.

Despite the heterogeneity of the available evidence base, some common themes emerged. 
Figure 1. Guidance flow diagram: pathway for managing long-term or recurring short-term or long-term sickness absence. ${ }^{3}$
Health problem

Assess and record occupation type and main duties; fitness to undertake duties; relationship between work, health, and sickness; any relevant advice or workplace support; the need for sickness absence

$\neg$

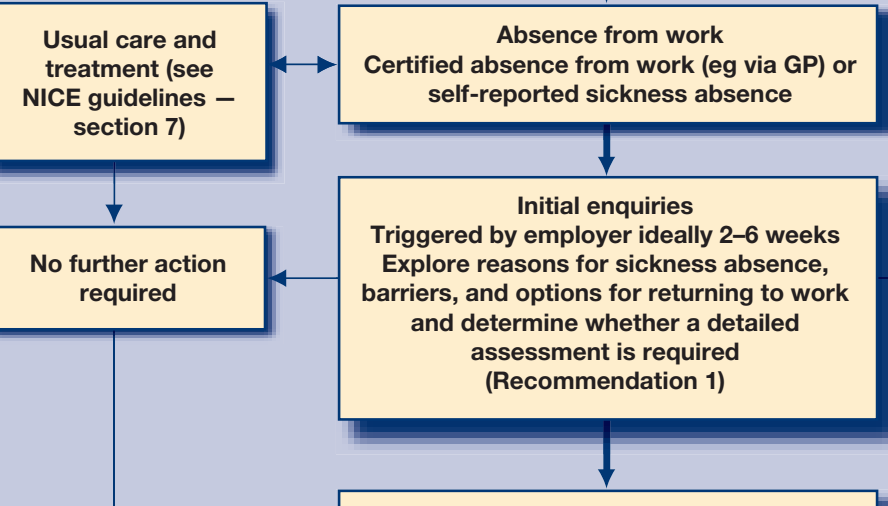

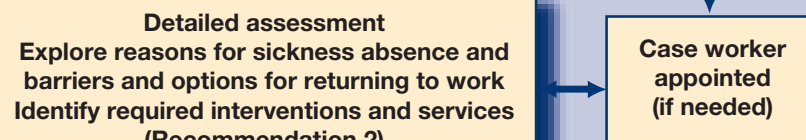

(Recommendation 2)
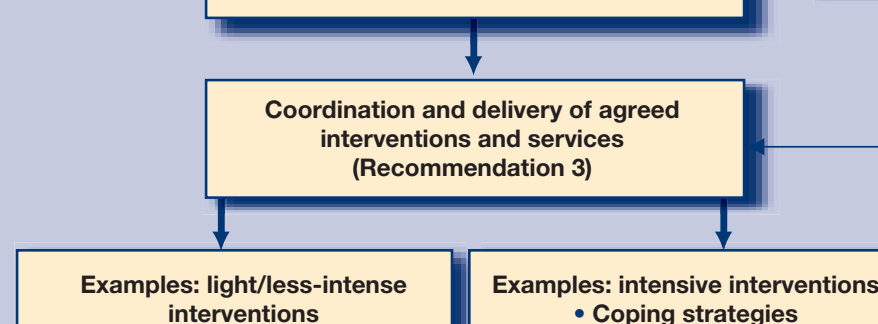

interventions

- Tailored advice

- Encouragement to be physically active

- Specialist referral (if needed)

(Recommendation 3)

- Psychological the

- Workplace modification

- Referral to specialist services

or vocational rehabilitation

(Recommendation 3)

Successful interventions appeared more likely to incorporate a range of perspectives but generally included a vocational rehabilitative element, and, for those experiencing sickness absence, early intervention and some form of direct contact with the workplace. The guidance is summarised using a flow diagram (Figure 1).

\section{DISCUSSION}

NICE guidance is primarily directed at a UK audience. Most of the research identified in the evidence reviews was undertaken in other European countries (particularly the Scandinavian countries), which have different sickness absence and social security systems, work environments, and cultural expectations. These may be important macro contexts influencing how interventions operate and their likely success. The importance of social context to the effectiveness of interventions has recently been shown in relation to cardiovascular risk factors; ${ }^{26}$ it is unlikely to be less important in relation to a complex social intervention such as return to work.

One issue in this vein, which received particular attention in PDG discussions, was the discrepancy between the health conditions of the UK sickness absence and incapacity benefits population and those studied in the international evaluations. Many of the studies in the international evidence base related to (male) participants with musculoskeletal conditions, whereas moderate mental health problems (particularly among women) are the biggest cause of sickness absence in the UK. ${ }^{15}$ It cannot be 
assumed that return to work interventions that work for one condition will also work for the other. A related issue was the fact that the included studies often related to very specific and homogeneous occupational groups (for example, male Finnish forestry workers, or female Danish nurses), and there were few general population studies. It was therefore not possible to determine any differences in the effects of interventions by socioeconomic or demographic group.

Although these contextual issues all clearly restrict the generalisability of the studies, conversely they also increase the international relevance of the resulting NICE guidance, based as it is on international best practice (applied to a UK setting). It also shows the important role of the PDG in judging, interpreting, and applying evidence when developing the guidance: it is not simply a case of evidence in and recommendations out.

The applicability of NICE guidance is also dependent on context, and this may be particularly problematic when guidance is developed from evidence derived from different populations or systems. For example, although there was clear scientific evidence to support the role of a case worker in making an early assessment of sickness absence and coordinating subsequent interventions to facilitate return to work, this is not currently routine practice in the UK. Access to appropriate training and adequate supervision and consultation with more skilled professionals, as recommended by the guidance, is likely to be patchy and inconsistent, as many employees do not currently have access to occupational health services, and those (usually larger) employers who do commission occupational health services do not necessarily choose to buy help with health aspects of sickness-absence management. ${ }^{27}$

However, part of the government's response to Dame Carol Black's review of the health of Britain's working-age people ${ }^{5}$ has been to commission" 'Fit for Work Service' pilots providing case management for job retention and rehabilitation. ${ }^{28}$ These pilots are spread throughout England, Scotland, and Wales, involve a variety of configurations, and will include national evaluation. This may help to provide UK evidence on the practical applicability of the case worker role in the context of NICE guidance.

The evidence that the NICE public health advisory committees have to deal with seldom fits neatly into the orthodoxy of the evidence-based medicine approach. The causal chains from intervention to outcome tend to be long and complicated, and much of the evidence deals with the relationship between the intervention and the outcome, and says precious little about the points in between. Many of the variables that are used to describe the evidence are the characteristics of group relationships rather than the characteristics of individuals, and do not fit easily with the idea of simple evidence accumulation and synthesis. Furthermore, the available evidence is often patchy and sometimes of less than ideal quality. ${ }^{29}$

Finally, the evidence reviewed for this guidance considered interventions that were delivered in a primary care and/or workplace setting. Although the emphasis was on work-related interventions, the review searches also identified some studies that contained evidence of the effectiveness of clinical (treatment-related) interventions delivered in the workplace or in primary care. The PDG recognised that many clinical interventions have outcomes that may impact on absenteeism rates or periods but this was not within the scope of this guidance. Consequently, such studies were excluded if it was not possible to disaggregate the return-to-workrelated outcomes of interest for this guidance from the treatment-related outcomes presented in the study.

Clinical practitioners should consider the impact of interventions and management options on work ability (absenteeism and presenteeism) for patients of working age. Indeed, this should be considered a key outcome for intervention studies. In turn, this would contribute greatly to the development of the evidence base for this topic. The emergence of new policies, such as the fit note and changing welfare benefit rules, ${ }^{30}$ raise the stakes in consultations for conversations about health and work and the implications of prolonged absence. There is increasing evidence that good work is good for health. ${ }^{18}$ GPs need to be more aware of their patients' employment (or worklessness), and the impact of health and illness upon this central aspect of their lives.

\section{Provenance}

Freely submitted, not externally peer reviewed.

\section{Competing interests}

The authors have stated that there are none.

\section{Acknowledgements}

Fellow members of the guideline development group, colleagues who provided evidence to the group, and staff at NICE who worked on the project.

\section{Discuss this article}

Contribute and read comments about this article on the Discussion Forum: http://www.rcgp.org.uk/bjgp-discuss

\section{REFERENCES}

1. Organisation for Economic Co-operation and Development (OECD). Sickness, disability and work: keeping on track in the economic downturn. Background paper. Paris: OECD, 2009. http://www.oecd.org/dataoecd/42/15/42699911.pdf (accessed 26 Jan 2011).

2. Boorman S. NHS health and well-being final report. London: Department of Health, 2009.

3. National Institute for Health and Clinical Excellence. Public health guidance 19. Management of long-term sickness absence and incapacity for work. London: National Institute for Health and Clinical Excellence, 2009. http://guidance.nice.org.uk/PH19 (accessed 26 Jan 2011) 
4. Department for Work and Pensions. Welfare Reform Bill. London: Crown Copyright, 2006.

http://www.dwp.gov.uk/aboutus/welfarereform/\#bill (accessed 26 Jan 2011).

5. Health, Work and Wellbeing Programme. Dame Carol Black's review of the health of Britain's working age population. Working for a healthier tomorrow. London: The Stationery Office, 2008

6. Organisation for Economic Co-operation and Development Transforming disability into ability: policies to promote work and income security for disabled people. Paris: Organisation for Economic Co-operation and Development, 2003.

7. Gimeno G, Benavides FG, Benach J, Amick BC III. Distribution of sickness absence in the European union countries. Occup Environ Med 2004; 61(10): 867-869.

8. Barham C, Begum N. Sickness absence from work in the UK. Labour market trends. London: Office for National Statistics, 2005.

9. Barham C, Leonard J. Trends and sources of data on sickness absence. Labour market trends. London: Office for National Statistics, 2002.

10. Woolf S, Martindale A-M, Stanistreet D, Gabbay M. DWP project on the feasibility of SSP data collection. Research report 427. London: Department for Work and Pensions, 2007.

11. Chartered Institute of Personnel and Development. Annual survey report 2009: absence management. London: Chartered Institute of Personnel and Development, 2008.

12. Confederation of British Industry. CBI/AXA absence and labour turnover survey. London: Confederation of British Industry, 2008.

13. Sainsbury Centre for Mental Health. Policy paper 8. Mental health at work: developing the business case. London: Sainsbury Centre for Mental Health, 2007.

14. Brown J, Smith J, Webster D, et al. Changes in incapacity benefit receipt in UK cities 2000-2008. University of Glasgow: Scottish Observatory for Work and Health, 2010.

15. Shiels C, Gabbay MB, Ford FM. Patient factors associated with duration of certified sickness absence and transition to long-term incapacity. Br J Gen Pract 2004; 54(499): 86-91.

16. Department of Health. Choosing health - making healthy choices easier. London: Department of Health, 2004.

17. Ministerial Task Force for Health, Safety and Productivity and the Cabinet Office. Managing sickness absence in the public sector. London: Health and Safety Executive, 2004.

18. Waddell, G, Burton A. Is work good for your health and wellbeing?
London: The Stationery Office, 2006.

19. Department for Works and Pensions. Incapacity benefit and severe disablement allowance: quarterly summary statistics. London: Department of Work and Pensions, 2005.

http://statistics.dwp.gov.uk/asd/asd1/ib_sda/index.php?page=ib_sd a_feb05 (accessed 7 Feb 2011).

20. Department for Works and Pensions. Incapacity benefit/severe disability allowance claimants - May 2007. London: Office for National Statistics, 2007.

21. Brown J, Hanlon P, Turok I, et al. Mental health as a reason for claiming incapacity benefit - a comparison of national and local trends. J Public Health (Oxf) 2009; 31(1): 74-80.

22. Prime Minister's Strategy Unit. Improving the life chances of disabled people. London: HMSO, 2005.

23. National Institute for Health and Clinical Excellence. Methods for development of NICE public health guidance. London: National Institute for Health and Clinical Excellence, 2006. http://www.nice.org.uk/media/FB9/59/PHMethodsManual2006.pd f (accessed 26 Jan 2011)

24. Skouen JS, Kvale A. Different outcomes in subgroups of patients with long-term musculoskeletal pain. Nor Epidemiol 2006; 16(2): 127-135.

25. Haldorsen EMH, Kronholm K, Skouen JS, Ursin H. Predictors for outcome of a multi-modal cognitive behavioural treatment program for low back pain patients - a 12-month follow-up study. Eur J Pain 1998; 2(4): 293-307.

26. Chow CK, Lock K, Teo K, et al. Environmental and societal influences acting on cardiovascular risk factors and disease at a population level: a review. Int J Epidemiol Advance 2009; 38(6): 1595-1598.

27. Nicholson PJ. Occupational health services in the UK challenges and opportunities. Occup Med 2004; 54(3): 147-152.

28. Department for Work and Pensions. Fit for Work Services. http://www.dwp.gov.uk/health-work-and-well-being/our-work/fitfor-work-services/ (accessed 7 Feb 2011).

29. Kelly MP, Morgan A, Ellis S, et al. Evidence based public health: A review of the experience of the National Institute of Health and Clinical Excellence (NICE) of developing public health guidance in England. Soc Sci Med 2010; 71(6): 1056-1062. http://dx.doi.org/10.1016/j.socscimed.2010.06.032 (accessed 26 Jan 2011).

30. Gabbay MB. Electronic fit notes: sickness certification in the new decade. Br J Gen Pract 2010; 60(573): 235-236. 